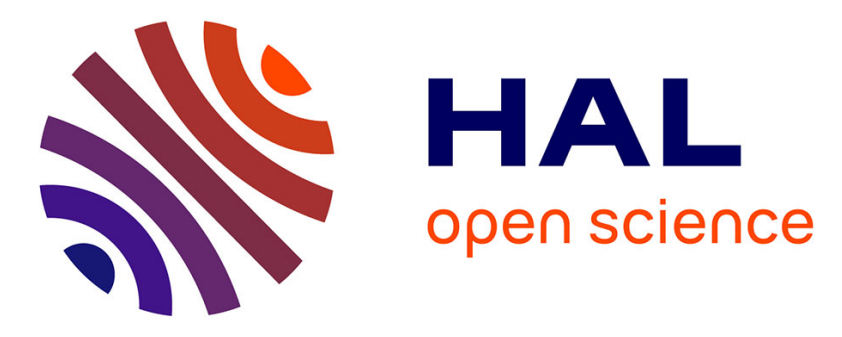

\title{
Mass Loading the Earth's Dayside Magnetopause Boundary Layer and Its Effect on Magnetic Reconnection
}

S. Fuselier, K J Trattner, S. Petrinec, M H Denton, S. Toledo-Redondo, M. André, Nicolas Aunai, C R Chappell, A Glocer, S. Haaland, et al.

\section{To cite this version:}

S. Fuselier, K J Trattner, S. Petrinec, M H Denton, S. Toledo-Redondo, et al.. Mass Loading the Earth's Dayside Magnetopause Boundary Layer and Its Effect on Magnetic Reconnection. Geophysical Research Letters, 2019, 46 (12), pp.6204-6213. 10.1029/2019GL082384 . hal-02372816

\section{HAL Id: hal-02372816 https://hal.science/hal-02372816}

Submitted on 20 Nov 2019

HAL is a multi-disciplinary open access archive for the deposit and dissemination of scientific research documents, whether they are published or not. The documents may come from teaching and research institutions in France or abroad, or from public or private research centers.
L'archive ouverte pluridisciplinaire HAL, est destinée au dépôt et à la diffusion de documents scientifiques de niveau recherche, publiés ou non, émanant des établissements d'enseignement et de recherche français ou étrangers, des laboratoires publics ou privés. 


\section{Geophysical Research Letters}

\section{RESEARCH LETTER \\ 10.1029/2019GL082384}

Key Points:

- During sustained periods of northward IMF, $\mathrm{O}^{+}$from the dayside high-latitude ionosphere mass loads the boundary layer adjacent to the magnetopause

- For the example shown, this mass loading is substantial and does have an effect on reconnection at the magnetopause when the IMF turns southward

- This mass loading causes a transient reduction in the reconnection rate but does not suppress reconnection at the magnetopause

Correspondence to:

S. A. Fuselier,

sfuselier@swri.edu

Citation:

Fuselier, S. A., Trattner, K. J., Petrinec S. M., Denton, M. H., Toledo-Redondo, S., André, M., et al. (2019). Mass loading the Earth's dayside magnetopause boundary layer and its effect on magnetic reconnection. Geophysical Research Letters, 46, 6204-6213. https:// doi.org/10.1029/2019GL082384

Received 6 FEB 2019 Accepted 30 MAY 2019 Accepted article online 5 JUN 2019 Published online 20 JUN 2019

\section{Mass Loading the Earth's Dayside Magnetopause Boundary Layer and Its Effect on Magnetic Reconnection}

\author{
S. A. Fuselier ${ }^{1,2}$ (D) K. J. Trattner ${ }^{3}$ (D), S. M. Petrinec ${ }^{4}$ (D) M. H. Denton ${ }^{5}$ (D) S. Toledo-Redondo ${ }^{6}$ (D),

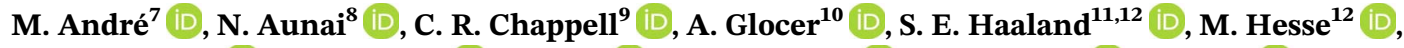

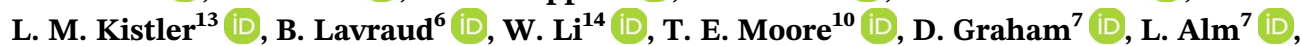

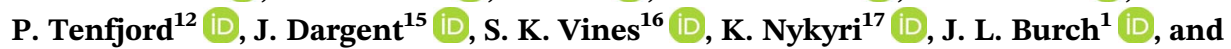 \\ R. J. Strangeway ${ }^{18}$ (iD)
}

${ }^{1}$ Southwest Research Institute, San Antonio, TX, USA, ${ }^{2}$ Department of Physics and Astronomy, University of Texas at San Antonio, San Antonio, TX, USA, ${ }^{3}$ Laboratory for Atmospheric and Space Physics, University of Colorado Boulder, Boulder, CO, USA, ${ }^{4}$ Lockheed Martin Advanced Technology Center, Palo Alto, CA, USA, ${ }^{5}$ New Mexico Consortium, Los Alamos, NM, USA, ${ }^{6}$ Institut de Recherche en Astrophysique et Planétologie, Université de Toulouse, CNRS, UPS, CNES, Toulouse, France, ${ }^{7}$ Swedish Institute of Space Physics, Uppsala, Sweden, ${ }^{8}$ Laboratoire de Physique des Plasmas, Paris, France, ${ }^{9}$ Physics and Astronomy Department, Vanderbilt University, Nashville, TN, USA, ${ }^{10}$ NASA Goddard Space Flight Center, Greenbelt, MD, USA, ${ }^{11}$ Max-Planck Institute for Solar Systems Research, Göttingen, Germany, ${ }^{12}$ Birkeland Center for Space Science, University of Bergen, Bergen, Norway, ${ }^{13}$ Institute for the Study of Earth Oceans and Space, University of New Hampshire, Durham, NH, USA, ${ }^{14}$ State Key Laboratory of Space Weather, National Space Science Center, Beijing, China, ${ }^{15}$ Physics Department E. Fermi, University of Pisa, Pisa, Italy, ${ }^{16}$ Applied Physics Laboratory, Johns Hopkins University, Laurel, MD, USA, ${ }^{17}$ Center for Space and Atmospheric Research, Embry-Riddle Aeronautical University, Daytona Beach, FL, USA, ${ }^{18}$ Earth and Space Sciences, University of California, Los Angeles, CA, USA

Abstract When the interplanetary magnetic field is northward for a period of time, $\mathrm{O}^{+}$from the high-latitude ionosphere escapes along reconnected magnetic field lines into the dayside magnetopause boundary layer. Dual-lobe reconnection closes these field lines, which traps $\mathrm{O}^{+}$and mass loads the boundary layer. This $\mathrm{O}^{+}$is an additional source of magnetospheric plasma that interacts with magnetosheath plasma through magnetic reconnection. This mass loading and interaction is illustrated through analysis of a magnetopause crossing by the Magnetospheric Multiscale spacecraft. While in the $\mathrm{O}^{+}$-rich boundary layer, the interplanetary magnetic field turns southward. As the Magnetospheric Multiscale spacecraft cross the high-shear magnetopause, reconnection signatures are observed. While the reconnection rate is likely reduced by the mass loading, reconnection is not suppressed at the magnetopause. The high-latitude dayside ionosphere is therefore a source of magnetospheric ions that contributes often to transient reduction in the reconnection rate at the dayside magnetopause.

\section{Introduction}

Magnetic reconnection at the Earth's magnetopause occurs between magnetosheath and magnetospheric magnetic fields and associated plasmas. The mean density in the magnetosheath at the subsolar magnetopause is $\sim 35 \mathrm{~cm}^{-3}$, while a typical density in the magnetosphere at that location (in the absence of cold, $<10 \mathrm{eV}$, plasma) is only $\sim 0.2-0.5 \mathrm{~cm}^{-3}$ (e.g., Cassak \& Fuselier, 2016; Kistler \& Mouikis, 2016). Thus, the shocked solar wind in the magnetosheath is the dominant plasma and reconnection at the magnetopause is highly asymmetric (e.g., Cassak \& Fuselier, 2016). However, there are multiple sources of magnetospheric ions and electrons; these sources are highly variable, and there are times and locations when one of these magnetospheric plasma sources may rival the magnetosheath source. During these times and at these locations, reconnection regions at the magnetopause may be modified (e.g., André et al., 2016; Dargent et al., 2017; Toledo-Redondo et al., 2016; Wang et al., 2014) and reconnection rates may be adversely affected (Cassak \& Shay, 2007).

Three sources of magnetospheric ions have been identified at the dayside magnetopause. The first is the ring current. This population of high-energy $(>10 \mathrm{keV})$ ions drifts from the magnetotail, around the dusk-flank magnetosphere, and to the dayside magnetopause. Typical ring current densities in the outer magnetosphere are $\sim 0.2-0.5 \mathrm{~cm}^{-3}$ (e.g., Kistler \& Mouikis, 2016). While the ring current consists of $\mathrm{H}^{+}$ and $\sim 10 \%$ heavy ions such as $\mathrm{He}^{+}, \mathrm{He}^{2+}$, and $\mathrm{O}^{+}$and the mass density is higher than $0.2 \mathrm{~cm}^{-3}$-amu 
(Daglis et al., 1999; Kistler \& Mouikis, 2016; Pulkkinen et al., 2001), this source does not reduce the reconnection rate significantly (i.e., by $>20 \%$ ).

The second magnetospheric ion source population is the plasmaspheric plume. When magnetospheric convection is enhanced, a plume of very cold $(\sim 1-10 \mathrm{eV})$, dense magnetospheric plasma forms on the duskside and extends sunward. A recent statistical study showed that this plume of cold plasma is observed in the outer magnetosphere and the magnetopause boundary layer (also known as the low-latitude boundary layer) predominantly at the duskside magnetopause (Fuselier et al., 2017). The plume consists of cold $\mathrm{H}^{+}$ and $\mathrm{He}^{+}$with much less $\mathrm{O}^{+}$(e.g., Berube et al., 2005; Horwtiz et al., 1986). Typical densities in the plume near geosynchronous orbit are $\sim 100 \mathrm{~cm}^{-3}$ (e.g., Borovsky \& Denton, 2008). The plasmaspheric density decreases as the flux tube expands toward the magnetopause, and densities of the order of $1-10 \mathrm{~cm}^{-3}$ are more common at the duskside boundary (e.g., Fuselier et al., 2017). However, much higher densities are possible at the magnetopause (Walsh et al., 2013), and, at times and in specific magnetopause locations, this magnetospheric source reduces the reconnection rate significantly.

The third magnetospheric ion source population is the warm plasma cloak (e.g., Chappell et al., 2008). This population of $\sim 10-\mathrm{eV}$ to several-kiloelectron-volt plasma originates in the nightside high-latitude ionosphere. Ions flow out of the ionosphere on the nightside and enter the near-Earth magnetotail. Once in the magnetotail, this ionospheric population convects around the dawn-flank magnetosphere and is observed predominantly at the duskside magnetopause (Fuselier et al., 2017). The warm plasma cloak consists of $\mathrm{H}^{+}$and $\mathrm{O}^{+}$with much less $\mathrm{He}^{+}$, that is, it reflects the composition of the nightside, high-latitude ion outflow. The dominance of $\mathrm{O}^{+}$over $\mathrm{He}^{+}$in the warm plasma cloak distinguishes this magnetospheric source from the plasmaspheric plume (Fuselier et al., 2017). At times, the mass density of the warm plasma cloak is a significant fraction of the magnetosheath source, and reconnection is reduced by $20 \%$ (Fuselier et al., 2016, 2017; Wang et al., 2015).

The characteristics of the plasmaspheric plume and warm plasma cloak sources and their possible effects on reconnection were recently surveyed using data from the Magnetospheric Multiscale (MMS) mission (Fuselier et al., 2017). This survey found that the plasmaspheric plume and warm plasma cloak sources have mass densities that are rarely as large as $\sim 50 \%$ of the magnetosheath densities. In the survey, $\mathrm{H}^{+}$densities greater than $1.5 \mathrm{~cm}^{-3}$ in the magnetosphere were used to identify warm plasma cloak intervals. No selection criterion was imposed on $\mathrm{O}^{+}$in the magnetopause boundary layer, and this lack of a criterion may have biased the results of the survey.

There are solar wind conditions that produce high $\mathrm{O}^{+}$densities in the dayside magnetopause boundary layer. One such condition is when the interplanetary magnetic field (IMF) is northward for an appreciable amount of time ( 10-20 min). Under this condition, high-latitude dual-lobe reconnection, ion outflow from the magnetospheric cusps, and sunward convection of reconnected field lines produce high $\mathrm{O}^{+}$densities in the magnetospheric boundary layer (Fuselier et al., 1989). The dayside high-latitude ionosphere therefore represents a fourth source of magnetospheric plasma at the dayside magnetopause.

Ion outflow from the dayside high-latitude ionosphere occurs for all IMF orientations. The cusp is a source of intense outflow of heated $\mathrm{O}^{+}$that has parallel flow velocities of $\sim 100 \mathrm{~km} / \mathrm{s}$ (e.g., Bouhram et al., 2004). Fluxes and energies of ion outflow from the cusp can be an order of magnitude greater than the outflow at lower latitude along closed field lines that thread the outer magnetosphere (Bouhram et al., 2004). For southward IMF, the ion outflow convects into the tail and may return to the dayside only after injection from the tail into the inner magnetosphere and convection from the nightside to the dayside. Plasma transport is very different for northward IMF. The key to the direct injection of $\mathrm{O}^{+}$into the magnetospheric boundary layer is the sunward convection of field lines reconnected at high latitudes and the closing of flux tubes on the dayside by dual-lobe reconnection during northward IMF.

The purpose of this paper is to use an event observed by the MMS spacecraft to demonstrate mass loading of the dayside magnetospheric boundary layer. In this event, a sustained interval of northward IMF mass loads the boundary layer through the aforementioned process. This northward IMF interval is followed by a rapid rotation of the magnetic field and a sustained interval of southward IMF. Although very high $\mathrm{O}^{+}$densities are observed in the boundary layer and the magnetospheric ion source rivals that in the magnetosheath, reconnection is still observed at the low-latitude magnetopause after the IMF rotates southward. 


\section{Observations}

Figure 1 shows solar wind magnetic field observations from the Wind spacecraft (panel a) and 40 min of observations from the Hot Plasma Composition Analyzer (Young et al., 2014) and magnetic field experiment on the MMS4 spacecraft (panels b to $i$ ) of a series of magnetopause crossings on 11 September 2015. Wind observations are convected to the subsolar magnetopause using the solar wind velocity and also the $\mathrm{B}_{\mathrm{Z}}$ rotation in the magnetosheath at 0913 UT. The MMS4 spacecraft was in the magnetosheath on the duskside Southern Hemisphere at the beginning of the 40-min interval and crossed the magnetopause several times before returning to the magnetosheath at the end of the interval. The IMF and the magnetic field in the magnetosheath rotated northward at 0913 UT and remained northward for $20 \mathrm{~min}$. As MMS4 approached the magnetopause, it observed a plasma depletion layer (e.g., Anderson et al., 1994; Fuselier et al., 2012; Zwan \& Wolf, 1976) characterized by an increase in the total field strength and a decrease in the $\mathrm{H}^{+}$density. A plasma depletion layer is formed at the magnetopause by magnetic field pileup at the boundary. Starting at 0927 UT and ending at 0933 UT, there are several low-shear magnetopause crossings. For all of these crossings, the proton velocity components and total magnetic field decrease from the magnetosheath to the boundary layer. From 0933 to 0943 UT, the spacecraft remained in the boundary layer. This boundary layer is characterized by unusually high $\mathrm{O}^{+}$density, nearly stagnant flow, and depressed magnetic field strength compared to the magnetosheath. The boundary layer has characteristics that are similar to those of diamagnetic cavities observed in the Earth's magnetospheric cusps. Although the MMS orbit does not go into the cusp proper, the spacecraft occasionally observe cusp-like cavities at midlatitudes away from the subsolar region (Nykyri et al., 2019). In these cavities, the total magnetic field strength is lower than the magnetosheath field strength and the high density of the plasma maintains the pressure balance.

While MMS is in the boundary layer, the IMF rotates southward. At 0943 UT, the MMS spacecraft crosses a high-shear magnetopause. Just before the crossing, there is a high-speed $\mathrm{H}^{+}$flow in the $-\mathrm{V}_{\mathrm{Z}}$ direction. These high-speed flows are also observed later, near high-shear magnetopause crossings at 0946:30 UT and 0948 UT. Flow jets in the boundary layer are indicative of magnetic reconnection at the magnetopause, and the flow direction indicates that the spacecraft was south of the reconnection $\mathrm{X}$ line.

In the magnetosheath from $0910 \mathrm{UT}$ to about $0927 \mathrm{UT}$, there is no $\mathrm{O}^{+}$in the energy range from approximately few electron volts to $40 \mathrm{keV}$. The contamination from the high $\mathrm{H}^{+}$fluxes that was not removed using the radio frequency system (see, Fuselier et al., 2016, 2017; Young et al., 2014) has been removed from Figure 1. In the boundary layer from 0933 to $0943 \mathrm{UT}$, the $\mathrm{O}^{+}$density is between 0.5 and $1 \mathrm{~cm}^{-3}$ or about a factor of 10 higher than the typical density near the magnetopause (e.g., Fuselier et al., 2017). Figure 2b shows that the $\mathrm{O}^{+}$ion population in the boundary layer is counterstreaming with velocities of the two peaks centered around \pm 150 to $\pm 200 \mathrm{~km} / \mathrm{s}$ (parallel and antiparallel to the magnetic field). This counterstreaming is a consequence of dual-lobe reconnection for northward IMF (Fuselier et al., 1989). Ionospheric $\mathrm{O}^{+}$outflow is energized to several kiloelectron volts by the rapid sunward motion of field lines that are reconnected poleward of the magnetospheric cusps. These ions flow along reconnected field lines to the dayside boundary layer. The counterstreaming $\mathrm{O}^{+}$in the dayside boundary layer is likely due to the fact that, for dual-lobe reconnection, previously open flux tubes poleward of the cusp now form closed flux tubes with $\mathrm{O}^{+}$streaming along the field from both high-latitude hemispheres. Alternatively, counterstreaming $\mathrm{O}^{+}$was recently observed in a cusp-like diamagnetic cavity for weakly southward IMF with strong IMF $B_{Y}$ (Nykyri et al., 2019). Under these conditions, ions flow out of the ionosphere and are locally trapped between the ionosphere and a magnetic field maximum in the subsolar region.

Figure 2a shows that the $\mathrm{H}^{+}$distribution is also counterstreaming but with higher velocities. For dual-lobe reconnection, these counterstreaming magnetosheath populations entered the boundary layer from the two reconnection sites poleward of the northern and southern cusps (e.g., Fuselier et al., 2014).

While in the magnetosheath (actually the magnetosheath boundary layer) from 0944 to 0946 UT and also after 0948 UT in Figure 1, MMS4 observed an $\mathrm{O}^{+}$population with an energy $>10 \mathrm{keV}$. Figure $2 \mathrm{~d}$ shows that this $\mathrm{O}^{+}$population is streaming parallel to the magnetic field. Figure $2 \mathrm{c}$ shows that there is also a $\mathrm{H}^{+}$population streaming parallel to the magnetic field. The ionospheric $\mathrm{O}^{+}$population is transmitted through the magnetopause and the magnetosheath $\mathrm{H}^{+}$population reflects off the magnetopause (see, e.g., Fuselier et al., 2018; Vines et al., 2017). These transmitted and reflected populations propagate southward or away 


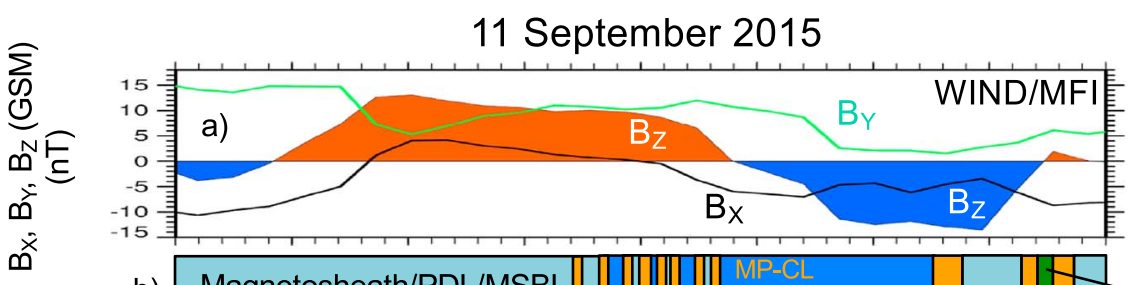

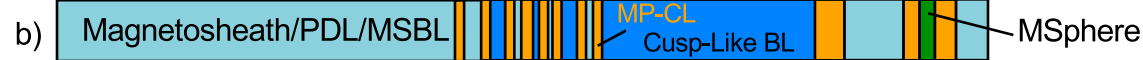
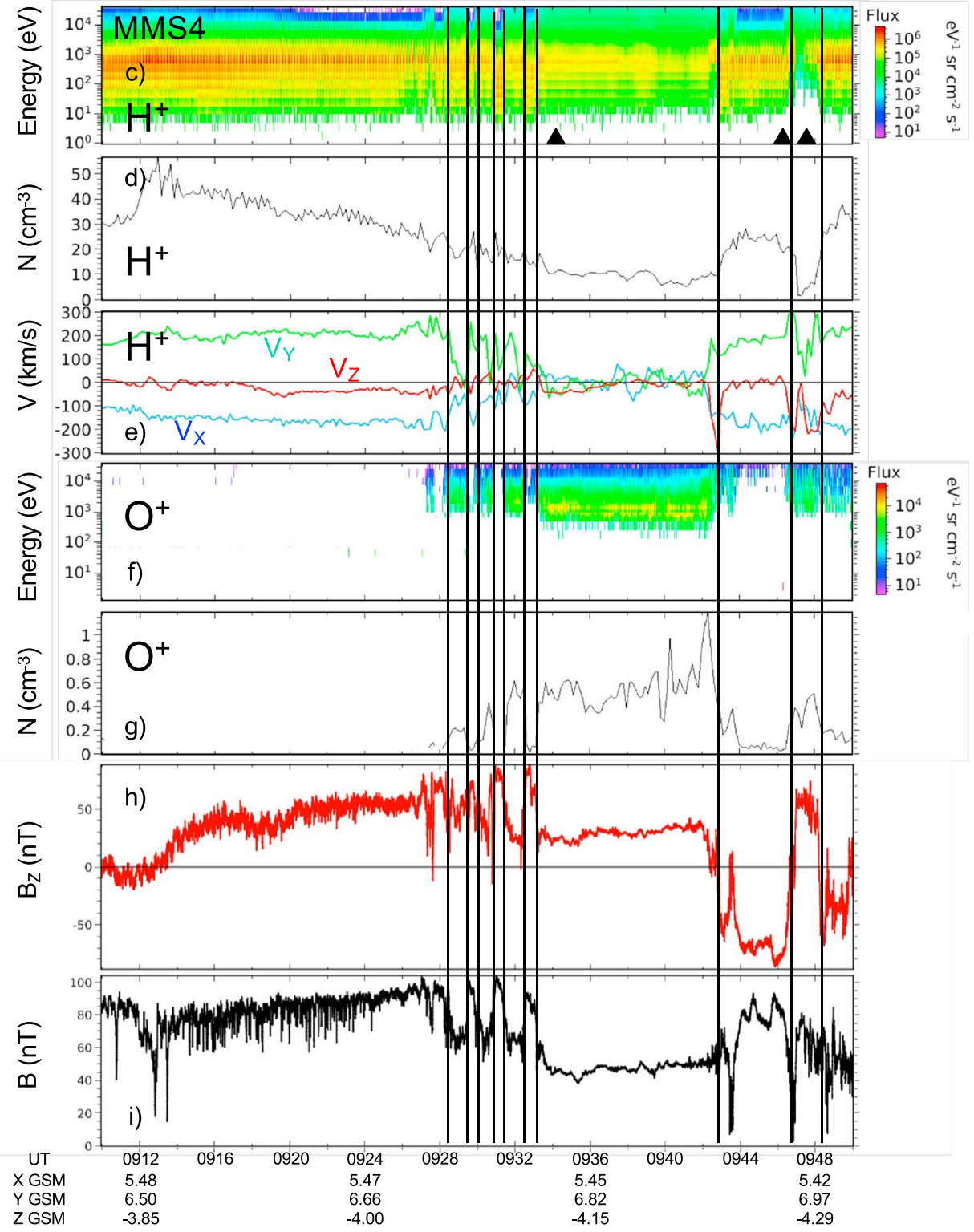

Figure 1. (top to bottom; a) The interplanetary magnetic field (IMF) components from the Wind/Magnetic Field Instrument (MFI) in geocentric solar magnetospheric (GSM) coordinates convected to the magnetopause, (b) plasma region identifier, (c) the $\mathrm{H}^{+}$omnidirectional flux from Hot Plasma Composition

Analyzer, (d) the $\mathrm{H}^{+}$density, (e) the $\mathrm{H}^{+}$velocity in near-geocentric solar ecliptic coordinates, (f) the $\mathrm{O}^{+}$flux, (g) the $\mathrm{O}^{+}$density, (h) the $B_{Z}$ GSM component, and (i) the total magnetic field from the Magnetospheric Multiscale (MMS) magnetic field experiment. The IMF was northward for almost 20 min prior to the multiple crossings of the magnetopause current layer (MP-CL) starting at 0928 UT. For these 20 minutes, the spacecraft was in the magnetosheath/Plasma Depletion Layer (PDL)/Magnetosheath Boundary Layer (MSBL). In the boundary layer (BL), MMS observed a very high $\mathrm{O}^{+}$density. MMS crossed the high magnetic shear magnetopause at 0943 UT because the IMF rotated southward while the spacecraft was in the boundary layer. At the high-shear magnetopause, the high-speed,

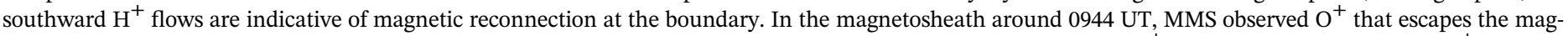
netosphere along open field lines. When it returned to the boundary layer starting at 0946:30 UT, it observed a lower $\mathrm{O}^{+}$density because some of the $\mathrm{O}^{+}$that mass loaded the boundary layer was lost to the magnetosheath through open field lines at the magnetopause. Triangles in the $\mathrm{H}^{+}$flux panel show times for selected distributions in Figure 2. 

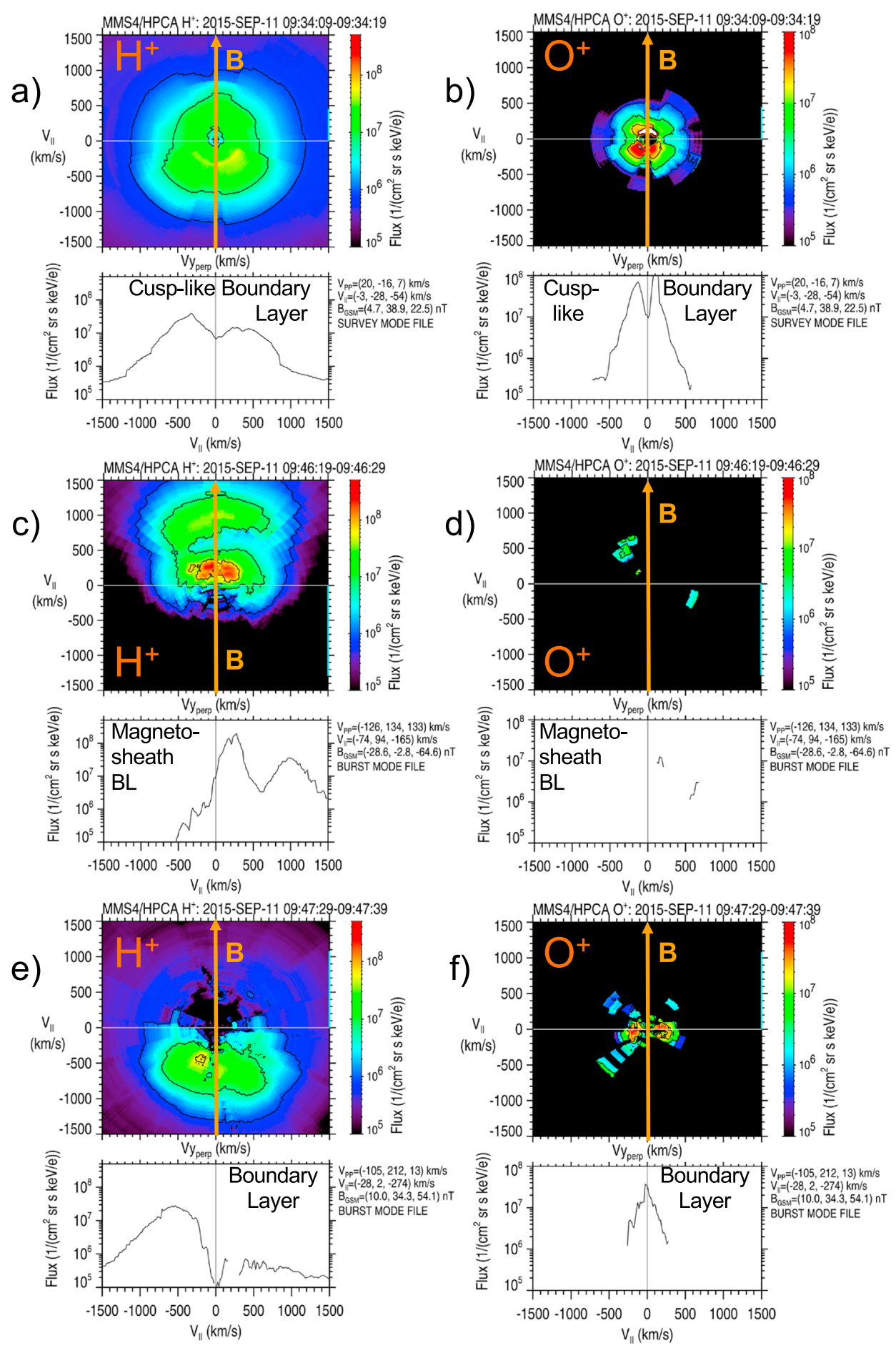

Figure $2 \mathrm{H}^{+}$and $\mathrm{O}^{+}$distribution functions for a 10-s intervals in the "cusp-like" boundary layer when the interplanetary magnetic field (IMF) was northward $(a, b)$ in the magnetosheath boundary layer when the IMF was southward (c, d) and in the magnetosphere boundary layer when the IMF was southward (e, f). Each panel shows a 2-D distribution in the parallel-perpendicular plane, and below the distribution, a 1-D cut along the parallel direction. All distributions are in the frame of reference where the bulk $\mathrm{H}^{+}$velocity perpendicular to the magnetic field is 0 . Panels a and $\mathrm{b}$ show counterstreaming similar to those observed in other boundary layer intervals when the IMF is northward. The $\mathrm{H}^{+}$and $\mathrm{O}^{+}$populations are streaming parallel and antiparallel to the field along a field line in the boundary layer that was closed by dual-lobe reconnection. When the IMF turns southward, the distributions on the magnetosheath side (c, d) and the magnetospheric side (e, $\mathrm{f}$ ) of the magnetopause are consistent with a single reconnection site northward of the spacecraft. The $\mathrm{H}^{+}$population streaming parallel to the field at about $1,000 \mathrm{~km} / \mathrm{s}$ in panel c reflected off the magnetopause, while the $\mathrm{H}^{+}$population streaming antiparallel to the field in panel e was transmitted across the open boundary. Similarly, the $\mathrm{O}^{+}$population in panel $\mathrm{d}$ was transmitted across the open magnetopause. MMS = Magnetospheric Multiscale; GSM = geocentric solar magnetospheric; HPCA = Hot Plasma Composition Analyzer. 
from the reconnection site that is north of the spacecraft. In the boundary layer between these two magnetosheath intervals, the $\mathrm{O}^{+}$density is lower than it was in the earlier boundary layer interval from 0933 to 0943 UT. Figures 2e and $2 \mathrm{f}$ show that the $\mathrm{H}^{+}$and $\mathrm{O}^{+}$populations in the boundary layer are no longer counterstreaming. The antiparallel streaming direction for the $\mathrm{H}^{+}$population is consistent with a reconnection site located northward of the spacecraft. There is also a brief encounter with the magnetosphere at 0947 UT. The $\mathrm{O}^{+}$density in the magnetosphere is about a factor of 2 lower than that in the nearby boundary layer at, for example, $0948 \mathrm{UT}$ and about a factor of 4 lower than the maximum $\mathrm{O}^{+}$density in the boundary layer at 0942 UT.

Figure 3 shows the model magnetic shear angles at the magnetopause at 0928 UT (top panel) and 0944 UT (bottom panel) when the IMF was northward and southward, respectively. The view is from the Sun and shear angles at the magnetopause are between the modeled draped magnetosheath field (the draped magnetosheath field lines are shown as the solid and dashed black curves in both panels) and the modeled magnetospheric magnetic field (see Trattner et al., 2007). The color scale extends from purple (very low shear) to red (very high shear). The black circle is the terminator. The blue lines show the predicted X line locations for the two time periods. The black curved lines (dashed and solid) show the draped magnetosheath magnetic field lines at the magnetopause. At 0928 UT, the MMS spacecraft is in a region of very low magnetic shear. It was connected to high-latitude reconnection X lines in the dusk sector, tailward of the northern cusp and in the dawn sector tailward of the southern cusp. After the magnetic field turned southward, the antiparallel reconnection lines migrated from high to low latitudes and were connected by a component reconnection line. The model also indicates that MMS4 was connected to this component reconnection X line located northward of the spacecraft. This modeling is consistent with the observed flow direction of the reflected $\mathrm{H}^{+}$on the magnetosheath side of the magnetopause in Figure 2 and the flow direction of the high-speed $\mathrm{H}^{+}$ion jets in the magnetopause boundary layer in Figure 1 at 0943 UT, 0946 UT, and 0948 UT.

\section{Discussion and Conclusions}

Figure 4 shows a schematic of the process that mass loads the dayside boundary layer. When the IMF is northward, dual-lobe reconnection occurs poleward of both magnetospheric cusps. This dual-lobe reconnection does not occur simultaneously in the two hemispheres, but the end result is a closed field line on the dayside as shown in the left-hand panel in Figure 3. $\mathrm{O}^{+}$directly from the high-latitude, dayside ionosphere is trapped on these closed field lines. On these field lines, the $\mathrm{O}^{+}$density is higher than in the adjacent magnetosphere. Fuselier et al. (1989) observed about a factor-of- 2 enhancement in the $\mathrm{O}^{+}$density in the boundary layer compared to the magnetosheath. This enhancement is consistent with the observations in Figure 1. The $\mathrm{O}^{+}$density in the magnetosphere during the brief encounter at $0947 \mathrm{UT}$ in Figure 1 is about a factor of 2 to 4 times lower than the $\mathrm{O}^{+}$densities in the boundary layer intervals at 0933 to 0943 UT and 0948 UT.

Mass loading the magnetospheric boundary layer is analogous to mass loading of the Earth's magnetotail (e.g., Karimabadi et al., 2011; Kistler et al., 2005; Liu et al., 2015). In the tail, $\mathrm{O}^{+}$-rich ion outflow from dayside and nightside high latitudes is injected into the plasma sheet. Enhanced $\mathrm{O}^{+}$densities in the plasma sheet persist up to the initiation of near-Earth reconnection. After reconnection, the plasma sheet $\mathrm{O}^{+}$density is reduced (Liu et al., 2015).

On the dayside, the sunward convection of reconnected field lines injects ionospheric $\mathrm{O}^{+}$and $\mathrm{H}^{+}$directly into the dayside magnetopause boundary layer. Because ionospheric ions are injected from both hemispheres, they form energized, counterstreaming $\mathrm{O}^{+}$populations in the boundary layer. These counterstreaming populations form even when the reconnection in the two hemispheres is not simultaneous (Fuselier et al., 2014). Figure 2b shows that these populations are propagating along the magnetic field with velocities of \pm 150 to $\pm 200 \mathrm{~km} / \mathrm{s}$. Assuming these velocities are constant and assuming a field line length of $\sim 10 \mathrm{R}_{\mathrm{E}}$, ionospheric ions take $\sim 5-10 \mathrm{~min}$ to propagate to the subsolar region. Thus, at least $10 \mathrm{~min}$ of sustained northward IMF is required in order to mass load the flux tubes that thread the boundary layer all the way to the subsolar region. For the event in Figure 1, the IMF was northward for almost $20 \mathrm{~min}$. Alternatively, the counterstreaming $\mathrm{O}^{+}$populations could form through the process described in Nykyri et al. (2019) when the IMF had a large $B_{Y}$ component. In that case, the time required to form counterstreaming populations is shorter because there is a mirror point near the subsolar region. 


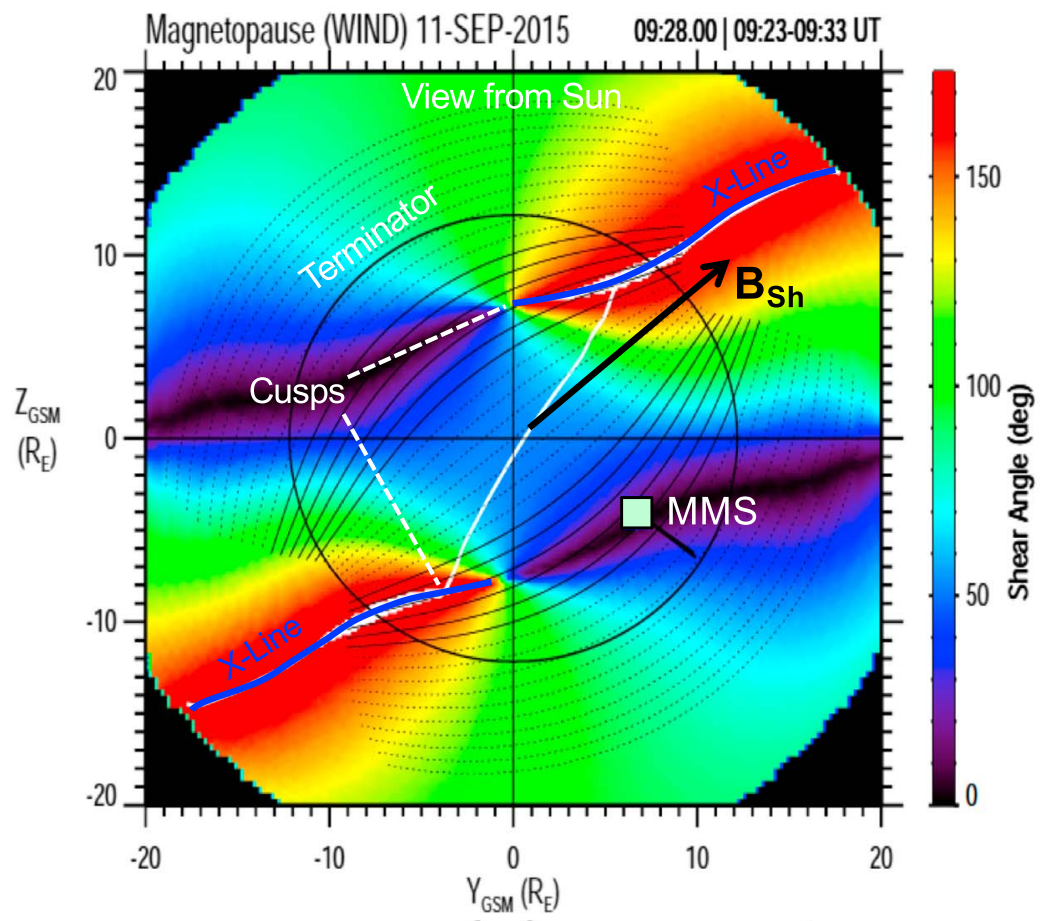

Parker-Spiral IMF-Clock Angle: $52^{0}\left(128^{\circ}\right) \quad B_{x}=-0.3 n T \quad B_{x} / B=-0.0 \quad n v^{2}=7.8 n P a(5.6)$ Dipol Titt: 1.1

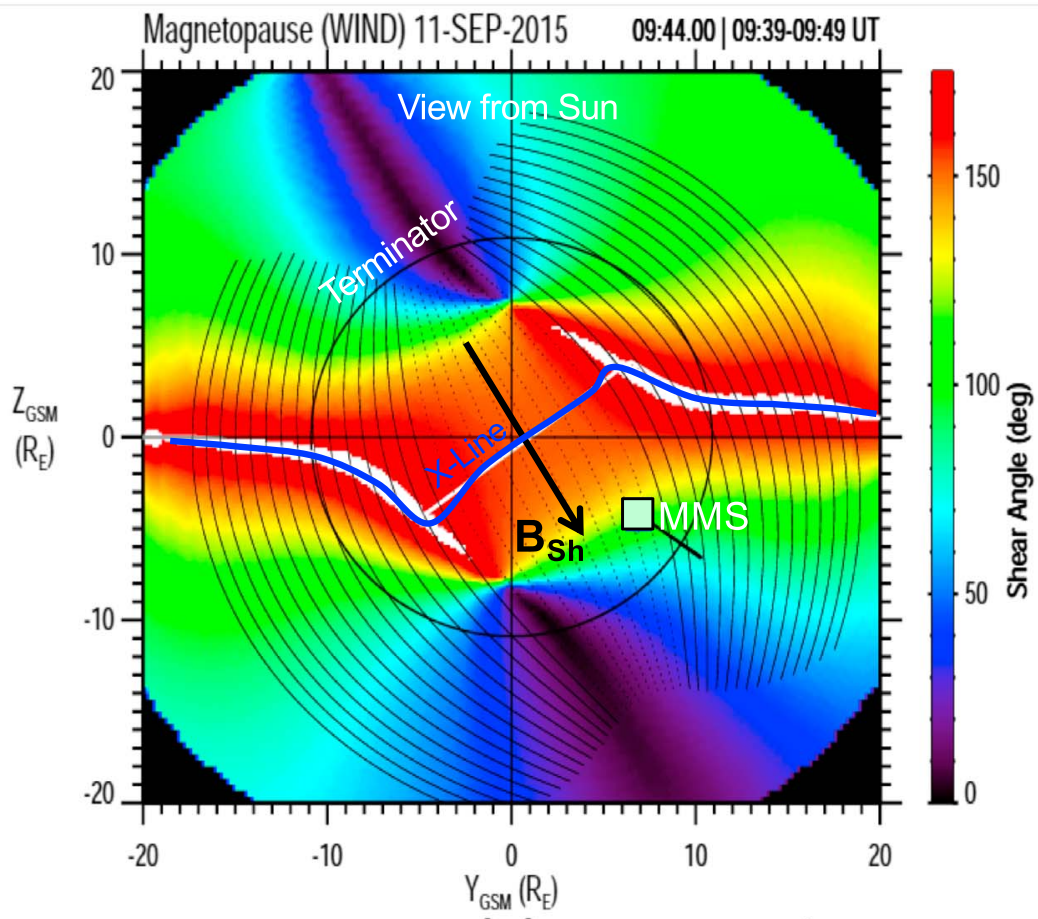

Parker-Spiral IMF-Clock Angle: $153^{0}\left(27^{0}\right) \quad B_{x}=-5.2 n T \quad B_{x} / B=-0.4 \quad n v^{2}=6.0 n P a(5.3)$ Dipol Tilt: 1.7

Figure 3. Model magnetic shear angles at the magnetopause at 0928 UT when the interplanetary magnetic field (IMF) was northward (top panel) and 0944 UT when the IMF was southward (bottom panel). When the IMF was northward, the Magnetospheric Multiscale (MMS) spacecraft was at the very low magnetic shear magnetopause. It was on magnetic field lines that reconnected at the Northern Hemisphere and Southern Hemisphere X lines. When the IMF was southward, the magnetic shear was much larger and the spacecraft was on field lines that connected to a nearly antiparallel reconnection $\mathrm{X}$ line northward of the spacecraft. The $-\mathrm{V}_{\mathrm{Z}} \mathrm{H}^{+}$flow at the high-shear magnetopause crossings in Figure 1 is consistent with this location of the $\mathrm{X}$ line. GSM = geocentric solar magnetospheric. 

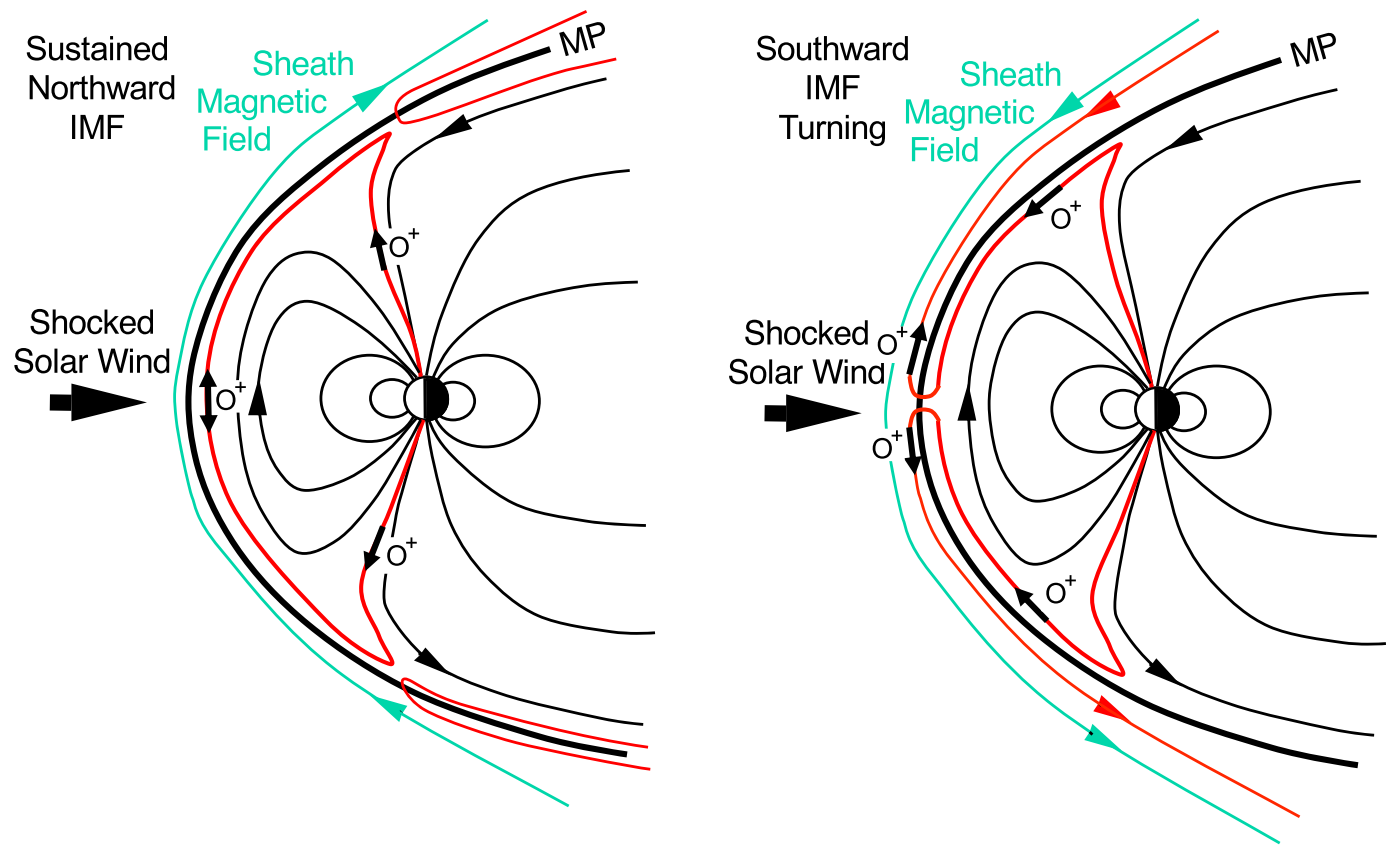

Figure 4. Schematic of the process that mass loads the dayside boundary layer. For simplicity, the schematic does not include an interplanetary magnetic field (IMF) $B_{Y}$ component. When the IMF is northward, dual-lobe reconnection poleward of both magnetospheric cusps produces closed field lines and ionospheric ions are injected onto reconnected field lines. The rapid sunward convection of the field lines energizes the ions and mass loads the flux tubes that thread the dayside boundary layer. When the IMF turns southward, reconnection occurs at low latitudes between the magnetosheath and the mass loaded boundary layer. $\mathrm{O}^{+}$in the boundary layer escapes along open field lines into the magnetosheath.

While the spacecraft was in the boundary layer, the IMF turned southward, weakly at first, but after 0937 UT, it was strongly southward. The spacecraft continued to observe a boundary layer that had characteristics associated with northward IMF conditions, up to about a minute before the spacecraft crossed the magnetopause at 0943 UT. This time lag is not surprising. First, there is considerable pileup of magnetic field with northward IMF orientation at the magnetopause, and it takes several minutes for these field lines to reconnect at the high-latitude magnetopause. This results in a delayed response time of the reconnection location to the change in the IMF orientation. A 6-min delay was measured recently for an IMF rotation event at the magnetopause (Trattner et al., 2016).

After an appropriate delay, the southward IMF turning caused the reconnection X line to migrate or move from high latitudes to low latitudes (see Figure 3). It is not clear if reconnection at low latitudes was affected initially by the high mass density boundary layer. The $\mathrm{O}^{+}$density was high in the boundary layer, and the average mass density just before the magnetopause crossing at 0943 UT was about two thirds of the mass density in the magnetosheath $\left(19.6 \mathrm{~cm}^{-3}\right.$-amu in the boundary layer vs. $28 \mathrm{~cm}^{-3}$-amu in the magnetosheath). Using the analysis in Fuselier et al. (2016), the high mass density in the boundary layer is predicted to result in a $\sim 32 \%$ reduction in the reconnection rate. Thus, while reconnection should be affected by the mass loaded boundary layer, observations show that it still occurs. Since there is no accurate way to measure the reconnection rate at the magnetopause for this event, it is not possible to verify observationally that the rate was reduced. The presence of $\mathrm{O}^{+}$also reduces the Alfven speed. For the two magnetopause crossings at 0943 UT and 0948 UT, the Alfven speed, modified by the fact that the reconnection is asymmetric and there is a guide field (see, for example, Cassak \& Fuselier, 2016), was 250 and $260 \mathrm{~km} / \mathrm{s}$, respectively. Without the contribution from $\mathrm{O}^{+}$, the modified Alfven speed would have been about $280 \mathrm{~km} / \mathrm{s}$ for both crossings. In Figure 2e, the reconnection jet speeds in the $Z$ direction for the crossing at 0943 UT and 0948 UT were 280 and $210 \mathrm{~km} / \mathrm{s}$, respectively. Thus, similar to the conclusions from Walsh et al. (2013), the presence of magnetospheric ions reduces the Alfven speed and the observed outflow speeds are approximately equal to the lower Alfven speeds at the two crossings.

It is clear that reconnection occurred at the magnetopause during the MMS crossings. Figure 1 shows that there are high-speed ion jets at the magnetopause crossings at 0942:30 UT, 0946:30 UT, and 0948 UT. 
Furthermore, the $\mathrm{O}^{+}$and $\mathrm{H}^{+}$distributions in Figure 2 on the magnetosheath and magnetospheric sides of the magnetopause are consistent with a reconnection site northward of the spacecraft. The propagation of $\mathrm{O}^{+}$on open field lines into the magnetosheath is illustrated schematically in the right-hand panel of Figure 4. Upon return to the boundary layer at 0946:30 UT, or about 4 min later, the spacecraft observes an $\mathrm{O}^{+}$density that is reduced by about one half compared to the boundary layer interval from 0933 to 0943 UT. The reduction in the $\mathrm{O}^{+}$density is analogous to the loss of $\mathrm{O}^{+}$in the mass-loaded plasma sheet in the magnetotail after the onset of reconnection (Karimabadi et al., 2011; Liu et al., 2015). At both the magnetopause and in the magnetotail, $\mathrm{O}^{+}$leaves the region along open field lines. The timescales for the loss of $\mathrm{O}^{+}$in the tail and on the dayside are very different. At the velocities parallel to the magnetic field in Figure 2, the $\mathrm{O}^{+}$population propagates from the ionosphere to the dayside boundary layer in approximately 5-10 min. Thus, when boundary layer field line opens with the southward turning, the $\mathrm{O}^{+}$population would drain from the field in approximately the same time. The loss of approximately half of the $\mathrm{O}^{+}$during the approximately 4 min that the spacecraft spent in the magnetosheath from 0943 UT to 0946:30 UT is consistent with this timing.

In summary, the event in Figure 1 demonstrates that there is a fourth source of magnetospheric plasma at the dayside magnetopause. The other three sources (ring current, plasmaspheric plume, and warm plasma cloak) all arrive at the magnetopause via convection or drift from the magnetotail or inner magnetosphere. This fourth source is injected directly from the high-latitude dayside ionosphere into the magnetopause boundary layer as long as the IMF remains northward for 10 to $20 \mathrm{~min}$. Because the source is confined to the boundary layer, it has a transient effect on reconnection at the dayside magnetopause.

\section{Acknowledgments}

This study was facilitated by the International Space Science Institute (ISSI) through the research team studying cold plasma of ionospheric origin. The MMS mission has been a tremendous success, and the many women and men who helped create this mission share in this success. All MMS data are accessible through the MMS science data center (https://lasp. colorado.edu $/ \mathrm{mms} / \mathrm{sdc} /$ ). Solar wind data are from the Wind spacecraft and were obtained through the CDAWeb. Research at Southwest Research Institute was funded by NASA through MMS prime contract NNG04EB99C.

\section{References}

Anderson, B. J., Fuselier, S. A., Gary, S. P., \& Denton, R. E. (1994). Magnetic spectral signatures in the Earth's magnetosheath and plasma depletion layer. Journal of Geophysical Research, 99(A4), 5877. https://doi.org/10.1029/93JA02827

André, M., Li, W., Toledo-Redondo, S., Khotyaintsev, Y. V., Vaivads, A., Graham, D. B., et al. (2016). Magnetic reconnection and modification of the Hall physics due to cold ions at the magnetopause. Geophysical Research Letters, 43, 6705-6712. https://doi.org/10.1002/ 2016GL069665

Berube, D., Moldwin, M. B., Fung, S. F., \& Green, J. L. (2005). A plasmaspheric mass density model and constraints on its heavy ion concentration. Journal of Geophysical Research, 110, A04212. https://doi.org/10.1029/2004JA010684

Borovsky, J. E., \& Denton, M. H. (2008). A statistical look at plasmaspheric drainage plumes. Journal of Geophysical Research, 113, A09221. https://doi.org/10.1029/2007JA012994

Bouhram, M., Klecker, B., Miyake, W., Rème, H., Sauvaud, J. A., Malingre, M., et al. (2004). On the altitude dependence of transversely heated O+ distributions in the cusp/cleft. Annales Geophysicae, 22(5), 1787-1798. https://doi.org/10.5194/angeo-22-1787-2004

Cassak, P. A., \& Fuselier, S. A. (2016). Reconnection at Earth's dayside magnetopause. In W. Gonzalez \& E. Parker (Eds.), Magnetic Reconnection, Astrophys. and Space Sci Library (Vol. 427, pp. 213-276). Switzerland: Springer. https://doi.org/10.1007/978-3-31926432-5

Cassak, P. A., \& Shay, M. A. (2007). Scaling of asymmetric magnetic reconnection: General theory and collisional simulations. Physics of Plasmas, 14(10), 102114. https://doi.org/10.1063/1.2795630

Chappell, C. R., Huddleston, M. M., Moore, T. E., Giles, B. L., \& Delcourt, D. C. (2008). Observations of the warm plasma cloak and an explanation of its formation in the magnetosphere. Journal of Geophysical Research, 113, A09206. https://doi.org/10.1029/2007JA012945

Daglis, I. A., Thorne, R. M., Baumjohann, W., \& Orsini, S. (1999). The terrestrial ring current: Origin, formation, and decay. Reviews of Geophysics, 37(4), 407-438. https://doi.org/10.1029/1999RG900009

Dargent, J., Aunai, N., Lavraud, B., Toledo-Redondo, S., Shay, M. A., Cassak, P. A., \& Malakit, K. (2017). Kinetic simulation of asymmetric magnetic reconnection with cold ions. Journal of Geophysical Research: Space Physics, 122, 5290-5306. https://doi.org/10.1002/ 2016JA023831

Fuselier, S. A., Burch, J. L., Cassak, P. A., Goldstein, J., Gomez, R. G., Goodrich, K., et al. (2016). Magnetospheric ion influence on magnetic reconnection at the duskside magnetopause. Geophysical Research Letters, 43, 1435-1442. https://doi.org/10.1002/ 2015GL067358

Fuselier, S. A., Burch, J. L., Mukherjee, J., Genestreti, K. J., Vines, S. K., Gomez, R., et al. (2017). Magnetospheric ion influence at the dayside magnetopause. Journal of Geophysical Research: Space Physics, 122, 8617-8631. https://doi.org/10.1002/2017JA024515

Fuselier, S. A., Klumpar, D. M., Peterson, W. K., \& Shelley, E. G. (1989). Direct injection of ionospheric $\mathrm{O}^{+}$into the dayside low latitude boundary layer. Geophysical Research Letters, 16(10), 1121-1124. https://doi.org/10.1029/GL016i010p01121

Fuselier, S. A., Petrinec, S. M., Trattner, K. J., Broll, J. M., Burch, J. L., Giles, B. L., et al. (2018). Observational evidence of large-scale multiple reconnection at the Earth's dayside magnetopause. Journal of Geophysical Research: Space Physics, 123, 8407-8421. https://doi. org/10.1029/2018JA025681

Fuselier, S. A., Petrinec, S. M., Trattner, K. J., \& Lavraud, B. (2014). Magnetic field topology for northward IMF reconnection: Ion observations. Journal of Geophysical Research: Space Physics, 119, 9051-9071. https://doi.org/10.1002/2014JA020351

Fuselier, S. A., Trattner, K. J., Petrinec, S. M., \& Lavraud, B. (2012). Dayside magnetic topology at the Earth's magnetopause for northward IMF. Journal of Geophysical Research, 117, A08235. https://doi.org/10.1029/2012JA017852

Horwtiz, J. L., Comfort, R. H., \& Chappell, C. R. (1986). Plasmasphere and plasmapause region characteristics as measured by DE-1. Advances in Space Research, 6(3), 21-29. https://doi.org/10.1016/0273-1177(86)90313-3

Karimabadi, H., Roytershteyn, B., Mouikis, C. G., Kistler, L. M., \& Daughton, W. (2011). Flushing effect in reconnection: Effects of minority species of oxygen ions. Planetary and Space Science, 59(7), 526-536. https://doi.org/10.1016/j.pss.2010.07.014 
Kistler, L. M., Mouikis, C., Möbius, E., Klecker, B., Sauvaud, J. A., Réme, H., et al. (2005). Contribution of nonadiabatic ions to the cross-tail current in an $\mathrm{O}^{+}$dominated thin current sheet. Journal of Geophysical Research, 110, A06213. https://doi.org/10.1029/2004JA010653

Kistler, L. M., \& Mouikis, C. G. (2016). The inner magnetosphere ion composition and local time distribution over a solar cycle. Journal of Geophysical Research: Space Physics, 121, 2009-2032. https://doi.org/10.1002/2015JA021883

Liu, Y. H., Mouikis, C. G., Kistler, L. M., Wang, S., Roytershteyn, V., \& Karimabadi, H. (2015). The heavy ion diffusion region in magnetic reconnection in the Earth's magnetotail. Journal of Geophysical Research: Space Physics, 120, 3535-3551. https://doi.org/10.1002/ 2015JA020982

Nykyri, K., Chu, C., Ma, X., Fuselier, S. A., \& Rice, R. (2019). First MMS observation of energetic particles trapped in high-latitude magnetic field depressions. Journal of Geophysical Research: Space Physics, 124, 197-210. https://doi.org/10.1029/2018JA026131

Pulkkinen, T. I., Ganushkina, N. Y., Baker, D. N., Turner, N. E., Fennell, J. F., Roeder, J., et al. (2001). Ring current ion composition during solar minimum and rising solar activity: Polar/CAMMICE/MICS. Journal of Geophysical Research, 106(A9), 19,131-19,147. https://doi. org/10.1029/2000JA003036

Toledo-Redondo, S., André, M., Khotyaintsev, Y. V., Vaivads, A., Walsh, A., Li, W., et al. (2016). Cold ion demagnetization near the X line of magnetic reconnection. Geophysical Research Letters, 43, 6759-6767. https://doi.org/10.1002/2016GL069877

Trattner, K. J., Burch, J. L., Ergun, R., Fuselier, S. A., Gomez, R. G., Lewis, W. S., et al. (2016). The response time of the magnetopause reconnection location to changes in the solar wind: MMS case study. Geophysical Research Letters, 43, 4673-4682. https://doi.org/ 10.1002/2016GL068554

Trattner, K. J., Mulcock, J. S., Petrinec, S. M., \& Fuselier, S. A. (2007). Location of the reconnection line at the magnetopause during southward IMF conditions. Geophysical Research Letters, 34, L03108. https://doi.org/10.1029/2006GL028397

Vines, S. K., Fuselier, S. A., Trattner, K. J., Burch, J. L., Allen, R. C., Petrinec, S. M., et al. (2017). Magnetospheric ion evolution across the low-latitude boundary layer separatrix. Journal of Geophysical Research: Space Physics, 122, 10,247-10,262. https://doi.org/10.1002/ 2017JA024061

Walsh, B. M., Sibeck, D. G., Nishimura, Y., \& Angelopoulos, V. (2013). Statistical analysis of the plasmaspheric plume at the magnetopause. Journal of Geophysical Research: Space Physics, 118, 4844-4851. https://doi.org/10.1002/jgra.50458

Wang, S., Kistler, L. M., Mouikis, C. G., Liu, Y., \& Genestreti, K. J. (2014). Hot magnetospheric $\mathrm{O}^{+}$and cold ion behavior in magnetopause reconnection: Cluster observations. Journal of Geophysical Research: Space Physics, 119, 9601-9623. https://doi.org/10.1002/ 2014JA020402

Wang, S., Kistler, L. M., Mouikis, C. G., \& Petrinec, S. M. (2015). Dependence of the dayside magnetopause reconnection rate on local conditions. Journal of Geophysical Research: Space Physics, 120, 6386-6408. https://doi.org/10.1002/2015JA021524

Young, D. T., Burch, J. L., Gomez, R. G., De Los Santos, A., Miller, G. P., Wilson, P., et al. (2014). Hot plasma composition analyzer for the Magnetospheric Multiscale mission. Space Science Reviews, 199(1-4), 407-470. https://doi.org/10.1007/s11214-014-0049-6

Zwan, B. J., \& Wolf, R. A. (1976). Depletion of solar wind plasma near a planetary boundary. Journal of Geophysical Research, 81(10), 1636-1648. https://doi.org/10.1029/JA081i010p01636 